\title{
Ammonia in the upper gastrointestinal tract of man: Quantitations and relationships ${ }^{1}$
}

\author{
W. H. J. SUMMERSKILL, TOSHIO AOYAGI, AND WILLIAM B. EVANS \\ From the Gastrointestinal Research Unit, Mayo Clinic and Mayo Foundation, \\ and Mayo Graduate School of Medicine (University of Minnesota), Rochester, U.S.A.
}

EDITORIAL SYNOPSIS This paper concerns the concentration and output of ammonia in the stomach, duodenum, and jejunal juices in health and in various diseases. The effects of gastric, pancreatic, and biliary secretions are measured and it is suggested that ammonia undergoes non-ionic diffusion across the gut membrane relevant to the different $p \mathrm{H}$ levels. The place of upper gastrointestinal dialysis with acid is considered for the management of hyperammonaemia.

Management of the hepatic coma syndrome is based on the probability that nitrogenous material, particularly ammonia, derived from the gut is often of prime importance in pathogenesis (Butt and Summerskill, 1961; Sherlock, 1961). Although Bidder and Schmitt reported the presence of ammonia in the mammalian stomach more than a century ago (Huber, 1917), little is known of ammonia metabolism, or the factors influencing it, in the gastrointestinal tract of man (Chalmers, 1960). The purposes of this paper, therefore, are (1) to report on quantitation of ammonia concentrations and outputs in the upper gastrointestinal tract in health and in patients with disease of the liver or other disorders; (2) to report the effects of gastric or pancreatic secretion and bile on gastrointestinal ammonia content; and (3) to relate changes in concentrations of ammonia in the blood to those in the gut lumen.

\section{MATERIAL AND METHOD}

Observations were made on 54 healthy volunteers and 102 patients with miscellaneous diseases (Table I). The latter group contained 46 patients with hepatic cirrhosis, the diagnosis being evident on clinical grounds, supported by tests of hepatic function and confirmed when necessary by hepatic biopsy. In addition, six patients with free drainage of bile through $\mathrm{T}$ tubes and no evidence of hepatic disease were studied.

The augmented histamine test of Kay (1953) was performed as described by Scobie and Summerskill (1964). Augmented secretin tests were carried out by the method of Hartley, Gambill, and Summerskill (1965), using a Dreiling tube for simultaneous gastric and duo-

${ }^{1}$ This investigation was supported in part by research grant AM-06908 from the National Institutes of Health, Public Health Service. denal aspiration. Perfusions of the small intestine with isotonic Ringer's solution (Baxter Laboratories, Inc.) were performed with a five-lumen tube, which contained an occluding balloon; the $30-\mathrm{cm}$. segment of jejunum distal to the ligament of Treitz was selected and ammonia excretion was quantitated from two perfusion periods of 15 minutes each after a preliminary wash (Ewe and Summerskill, 1965).

Hyperammonaemia was induced during infusion, by vein, of ammonium chloride, $1 \mathrm{~g} . / 25 \mathrm{~kg}$. of body weight, in $5 \%$ solution of dextrose. Concentrations of ammonia in venous blood and in specimens from the gastrointestinal tract were measured without delay, by the method of Seligson and Hirahara (1957); the mean difference of duplicate determinations was $3.0 \mu \mathrm{g} . / 100 \mathrm{ml}$. ( $\pm 4 \cdot 3)$. All data are reported as mean values ( \pm standard error).

\section{RESULTS}

BASAL GASTRIC AMMONIA CONTENT The gradient between concentrations of ammonia in gastric juice and blood under basal circumstances was $17 \cdot 9( \pm 2 \cdot 3): 1$. Neither concentration differed significantly in relation to health and the disease processes studied but mean values for gastric ammonia concentration and output were highest in patients with the greatest acid output (Table I). No significant correlation between basal concentration or output of gastric ammonia and blood ammonia concentration, gastric $p \mathrm{H}$, or gastric acid output was established.

When hyperammonaemia was induced by infusing ammonium chloride by vein, both concentrations (Fig. 1) and outputs (Fig. 2) of gastric ammonia were increased; highly significant correlations existed between blood ammonia concentrations and gastric outputs $(r=0 \cdot 32)$ and concentrations $(r=$ 
TABLE I

BASAL AMMONIA SECRETION IN UPPER GASTROINTESTINAL TRACT (MEAN \pm S.E.)

\begin{tabular}{|c|c|c|c|c|c|}
\hline & $\begin{array}{l}\text { Ammonia } \\
\text { Output } \\
(\mu g / h r .)\end{array}$ & $\begin{array}{l}\text { Ammonia } \\
\text { Concentration } \\
\text { ( } \mu \mathrm{g} .100 \mathrm{ml} .)\end{array}$ & $\begin{array}{l}\text { Blood Ammonia } \\
\text { Concentration } \\
\text { ( } \mu \mathrm{g} . / \mathrm{ml} .)\end{array}$ & Gastric $\mathrm{pH}$ & $\begin{array}{l}\text { Gastric Acid } \\
\text { Output } \\
(m E q . / h r .)\end{array}$ \\
\hline $\begin{array}{l}\text { Stomach } \\
\text { Normal (26) } \\
\text { Hepatic disease (25) } \\
\text { Peptic ulcer (8) } \\
\text { Others (23) } \\
\text { Total (82) }\end{array}$ & $\begin{array}{r}956 \pm 232 \\
1,112 \pm 254 \\
1,964 \pm 758 \\
1,315 \pm 354 \\
1,215 \pm 172\end{array}$ & $\begin{array}{l}1,728 \pm 203 \\
2,218 \pm 432 \\
2,810 \pm 553 \\
2,579 \pm 138 \\
2,222 \pm 200\end{array}$ & $\begin{array}{l}102 \pm 7 \cdot 2 \\
128 \pm 11 \cdot 2 \\
111 \pm 9 \cdot 6 \\
124 \pm 6 \cdot 4 \\
117 \pm 4 \cdot 7\end{array}$ & $\begin{array}{l}3.2 \pm 1.2 \\
2.82 \pm 0.6 \\
2.48 \pm 0.9 \\
1.47 \pm 0.2 \\
2.54 \pm 0.4\end{array}$ & $\begin{array}{l}1.0 \pm 0.4 \\
1.44 \pm 0.8 \\
3.86 \pm 0.7 \\
5.48 \pm 3.9 \\
2.76 \pm 0.9\end{array}$ \\
\hline $\begin{array}{l}\text { Duodenum } \\
\text { Normal (15) } \\
\text { Hepatic disease (16) } \\
\text { Pancreatic disease (7) } \\
\text { Others (11) } \\
\text { Total (49) }\end{array}$ & $\begin{array}{l}472 \pm 146 \\
449 \pm 129 \\
242 \pm 143 \\
332 \pm 70 \\
386 \pm 63\end{array}$ & $\begin{array}{l}1,457 \pm 172 \\
1,517 \pm 311 \\
2,032 \pm 500 \\
1,294 \pm 235 \\
1,699 \pm 106\end{array}$ & $\begin{array}{l}114 \pm 7 \cdot 9 \\
122 \pm 10 \cdot 0 \\
122 \pm 10 \cdot 9 \\
114 \pm 9 \cdot 3 \\
119 \pm 3 \cdot 5\end{array}$ & & \\
\hline $\begin{array}{l}\text { Jejunum (perfusion) } \\
\text { Normal (13) } \\
\text { Cirrhosis (6) } \\
\text { Malabsorption (6) } \\
\text { Total (25) }\end{array}$ & $\begin{array}{l}4,798 \pm 366 \\
5,076 \pm 780 \\
5,412 \pm 1,344 \\
5,064 \pm 378\end{array}$ & $\begin{array}{l}560 \pm 40 \\
590 \pm 60 \\
600 \pm 120 \\
580 \pm 180\end{array}$ & $\begin{array}{l}100 \pm 7 \cdot 5 \\
117 \pm 11 \cdot 4 \\
128 \pm 18.0 \\
110 \pm 6 \cdot 6\end{array}$ & & \\
\hline
\end{tabular}

${ }^{1}$ Number of patients is given in parentheses.

$0 \cdot 85$ ) of ammonia. There was no consistent alteration in gastric $p \mathrm{H}$.

GASTRIC AMMONIA OUTPUT FOLLOWING STIMULATION OF GASTRIC SECRETION The augmented dose of histamine resulted in a significant increase in gastric output of ammonia ( $p<0.01)$ as well as of acid, when compared with the basal finding (Table II). Outputs of ammonia and acid (Fig. 3) correlated significantly $(r=0.57 ; p<0.05)$ under these circumstances. There was no change in concentrations of ammonia in the blood or gastric juice following the administration of histamine (Table II). Concentrations of ammonia in gastric juice measured in

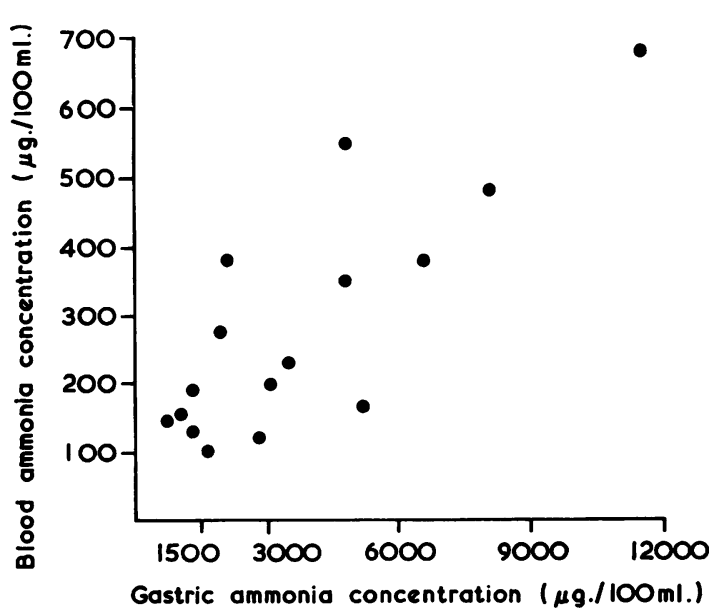

FIG. 1. Concentration of ammonia in blood and gastric juice during hyperammonaemia. six patients at 15 -minute intervals following stimulation of gastric secretion showed no significant change. Mean values of $3,575,2,407,2,147,2,358$, 2,064 , and $2,269 \mu \mathrm{g} . / 100 \mathrm{ml}$. were recorded during the 15 to 105 -minute period.

AMMONIA CONTENT OF DUODENUM The gradient between concentrations of ammonia in the distal duodenum and the blood was $11.5( \pm 1 \cdot 7): 1$. Basal ammonia output by the duodenum (Table I) was significantly less than that of the stomach $(p<0.001)$, and the mean duodenal concentration of ammonia was lower than the basal gastric concentration (Table I). Neither concentrations nor

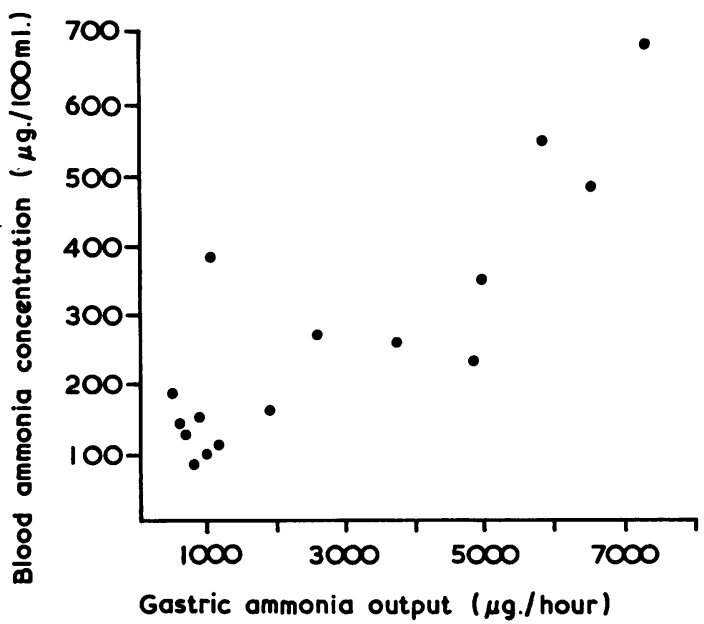

FIG. 2. Gastric ammonia output in relation to blood ammonia concentration. 
TABLE II

AMMONIA CONTENT OF GASTRIC SECRETION AND BLOOD BEFORE AND AFTER AUGMENTED DOSES OF HISTAMINE Basal (mean \pm S.E.)

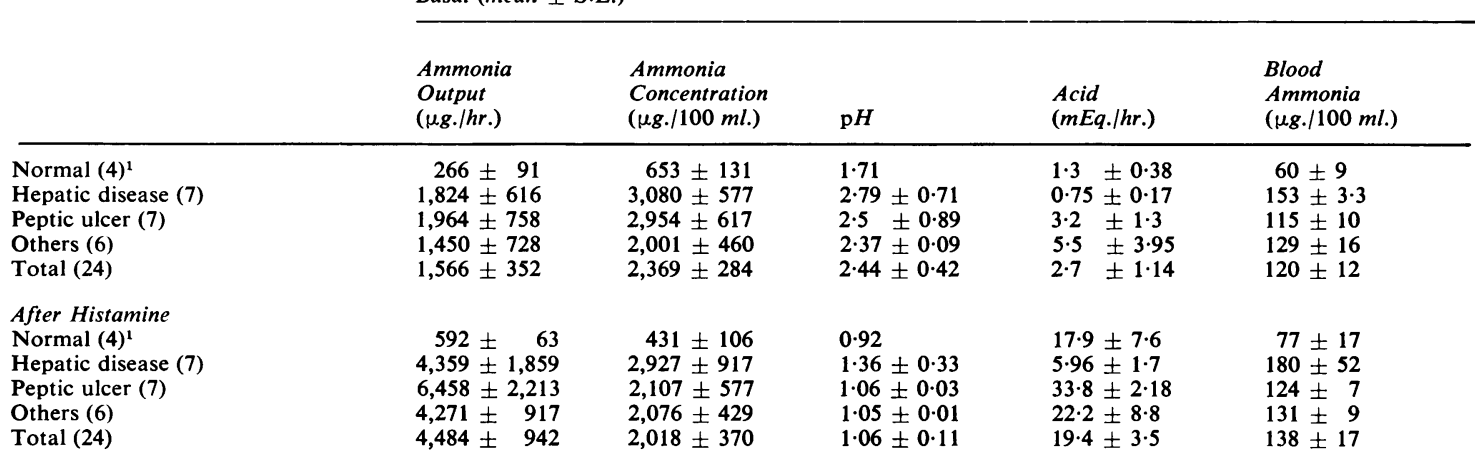

${ }^{1}$ Number of patients is given in parentheses.

TABLE III

AMMONIA CONTENT OF DUODENAL SECRETION AND BLOOD BEFORE AND AFTER AUGMENTED DOSE OF SECRETIN

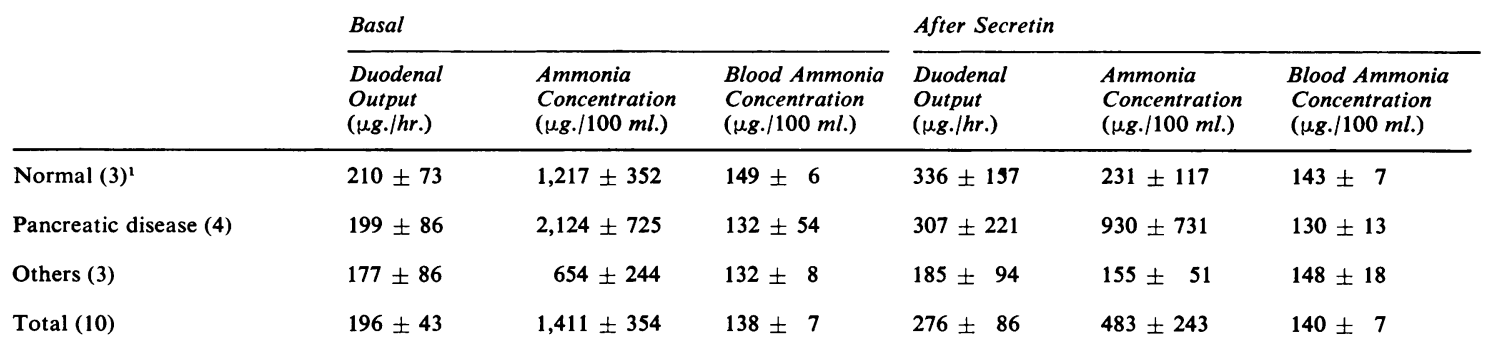

${ }^{1}$ Number of patients is given in parentheses.

outputs of ammonia in the duodenum differed significantly in health and in the disease processes studied (Table I).

Ammonia concentrations in T-tube bile were $134 \pm 16.3 \mu \mathrm{g} . / 100 \mathrm{ml}$. and were thus only slightly

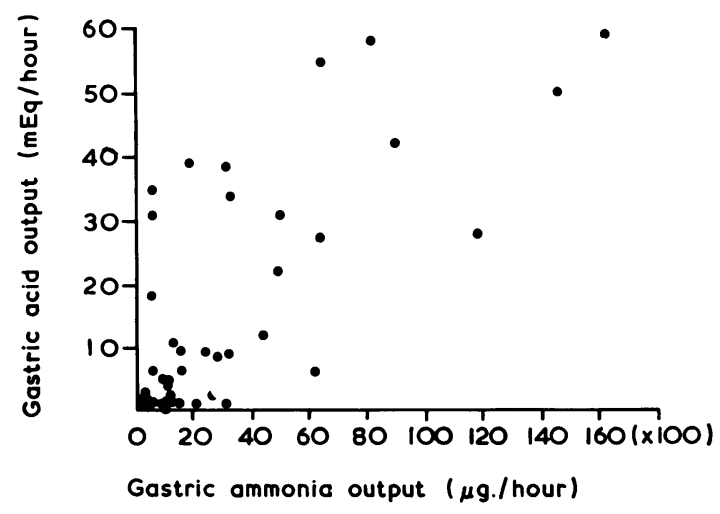

FIG. 3. Outputs of acid and ammonia by the stomach. higher $(p<0.05)$ than those in venous blood taken simultaneously from the same patients $(80 \pm 8.6$ $\mu g . / 100 \mathrm{ml}$.). Stimulation of volume and bicarbonate secretion by the pancreas with an augmented dose of secretin was followed by a fall in mean values for duodenal ammonia concentrations and a rise in mean duodenal ammonia output, in comparison with the fasting results (Table III). These changes were not significant and blood ammonia concentrations were not affected by secretin (Table III). Duodenal ammonia concentrations were greatest in patients with chronic pancreatitis, whose capacity for bicarbonate secretion was reduced.

AMMONIA SECRETION IN JEJUNUM During perfusion of the $30-\mathrm{cm}$. segment of jejunum, the gradient between basal concentrations of ammonia in the perfusate recovered and those in the blood was $5.9( \pm 0.5): 1$. Although blood concentrations were comparable, ammonia concentrations in the jejunal perfusate were less than those in the contents of the duodenum $(p<0.001)$ or stomach $(p<0.001)$ 


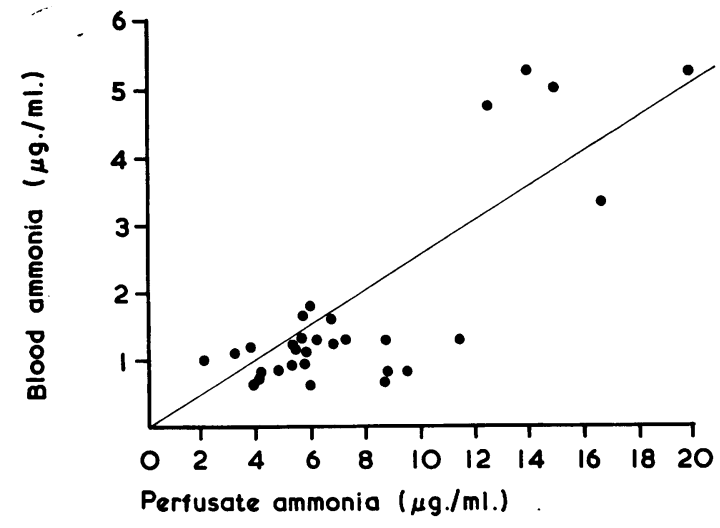

FIG. 4. Concentration of ammonia in blood and jejunal perfusate during hyperammonaemia.

(Table I). To the degree to which the situations were comparable, ammonia output of the $30-\mathrm{cm}$. jejunal segment far exceeded that of the duodenum $(p<0.001)$ or stomach $(p<0.001) \quad$ (Table 1$)$. Hyperammonaemia, induced by infusing ammonium chloride by vein, resulted in three-fold increases in concentrations and outputs of ammonia by the jejunal segment. There were highly significant correlations between concentrations of ammonia in the blood and concentrations $(r=0.81)$ (Fig. 4) and output $(r=0.80)$ of ammonia by the segment of jejunum. Despite ammonaemia of comparable degree, the increase over basal values in jejunal ammonia concentrations (Fig. 4) was significantly less $(p<0.05)$ than the corresponding increase in the stomach (Fig. 1).

\section{DISCUSSION}

Significant gradients exist between concentrations of ammonia in the blood and those in the stomach, duodenum, or jejunum. The activity of mucosal and bacterial enzymes liberating ammonia from nitrogenous material (Bessman, 1956) derived from the diet and blood, as well as from epithelial debris, probably contributes to the higher concentrations in the gut lumen. In addition, ammonia may be liberated by intestinal epithelial cells in animals as a result of metabolic work (Ingraham and Visscher, 1938). Passage of ammonia from blood to the gut, which was demonstrated most conclusively during hyperammonaemia, is also important. This process may reflect particularly the relative $p \mathrm{H}$, since distribution of ammonia between the circulation and the gastrointestinal tract will be influenced by non-ionic diffusion of dissociated ammonia to the more acid side (Milne, Scribner, and Crawford, 1958 ) of the gut membrane. Several results were consistent with such a mechanism. Thus, basal gastric ammonia concentrations were greater in the stomach than in the less acid duodenal and jejunal contents; and gastric ammonia output increased when gastric acid secretion was augmented by histamine. Also, ammonia concentrations in the stomach increased more than those in the jejunum during similar degrees of hyperammonaemia. Gradients in ammonia concentrations between blood and bile or the contents of the duodenum or jejunum are less susceptible to this explanation. High concentrations of ammonia in the jejunum occurred although the perfusate approximated neutrality, while a significant gradient between blood and duodenal ammonia concentrations persisted despite the alkaline $p \mathrm{H}$ associated with maximal bicarbonate secretion by the pancreas, following administration of secretin. Mean duodenal ammonia concentrations were greatest, however, in patients with pancreatic disease, whose capacity for bicarbonate secretion was most severely impaired.

Whether secretory processes in the upper gastrointestinal tract contribute to the greater ammonia content of the gut lumen is uncertain. Neither pancreatic secretion evoked by secretin, nor bile from T-tube drainage, contained concentrations of ammonia as high as those present in the duodenum under basal circumstances. The increased gastric ammonia output accompanying stimulation of gastric secretion could reflect the more acid intragastric $p \mathrm{H}$; however, the possibility that ammonia is an actively transported component of parietal or non-parietal cell secretion cannot be excluded. It is less likely that a 'wash-out' of ammonia was involved since gastric ammonia concentrations were maintained throughout the period of gastric secretory stimulation. Concentrations, but not outputs, of gastric ammonia have been reported by others (FitzGerald and Murphy, 1950; Huber, 1917; Lieber and Lefèvre, 1959; Mossberg, Thayer, and Spiro, 1963), and our findings are similar to those of Rappoport and Kern (1963). In health, ammonia is unlikely to contribute importantly to the neutralization of hydrochloric acid secretion and may be precluded from participating in acid-base equilibrium at the $p \mathrm{H}$ of the stomach (Mossberg et al., 1963). By contrast, the increased production of gastric ammonia in azotaemia, which is believed to reflect gastric urease activity, has been proposed (Lieber and Lefèvre, 1959) and refuted (Mossberg et al., 1963) as a cause of hypochlorhydria in uraemia.

The ready passage of ammonia from blood to gut lumen and the high concentrations of ammonia in gut contents prompt consideration of the upper gastrointestinal tract as a site for dialysis in the 
management of hyperammonaemia; ammonia removal should be enhanced by perfusion of the gut with an acid solution. The greater ammonia output by the stomach following stimulation of acid secretion may also have practical implication in this regard. However, the use of histamine to augment gastric ammonia output in patients with hepatic disease may be limited by a seemingly paradoxical tendency for this drug to precipitate hyperammonaemia (Turner and Arpad, 1963), although no evidence of such an action was found in the present study.

\section{SUMMARY}

Concentrations and outputs of ammonia in the stomach, duodenum, and jejunum were quantitated in health and in various disease states. High concentration gradients between the gastrointestinal tract and the blood were found under basal circumstances, and the effects of certain secretions (gastric, pancreatic, and biliary) upon the ammonia content of the upper gastrointestinal tract were measured. Of the factors pertaining to ammonia production in the upper gastrointestinal tract that were considered, passage of ammonia from blood to the gut lumen appeared particularly important. Most of the findings in this regard were consistent with non-ionic diffusion of ammonia due to the relative $p \mathrm{H}$ on different sides of the gut membrane. A possible practical application of the findings to the treatment of hyperammonaemia is discussed.

We are grateful to Drs. K. Ewe, R. C. Hartley, and B.A. Scobie who assisted in the collection of data during studies carried out in this department and reported elsewhere.

\section{REFERENCES}

Bessman, S. P. (1956). Ammonia metabolism in animals. In A Symposium on Inorganic Nitrogen Metabolism: Function of Metalloflavoproteins, edited by W. D. McElroy and B. Glass, pp. 408-437. Johns Hopkins Press, Baltimore.

Bidder and Schmitt. Quoted by Huber, H. L.

Butt, H. R., and Summerskill, W. H. J. (1961). Hepatic coma. Progr. Liver Dis, 1, 109-118.

Chalmers, T. C. (1960). Pathogenesis and treatment of hepatic failure. New Engl. J. Med., 263, 23-30; 77-82.

Ewe, K., and Summerskill, W. H. J. (1965). Transfer of ammonia in the human jejunum. J. Lab. clin. Med., 65, 839-847.

FitzGerald, O., and Murphy, P. (1950). Studies on the physiological chemistry and clinical significance of urease and urea with special references to the stomach. Part I. The distribution of urease with particular reference to the stomach. Irish J. Med. Sci., 97-138.

Hartley, R. C., Gambill, E. E., and Summerskill, W. H. J. (1965). Pancreatic volume and bicarbonate output with augmented doses of secretin. Gastroenterology, 48, 312-317.

Huber, H. L. (1917). Contributions to the physiology of the stomach. XL. The ammonia of the gastric juice. Amer. J. Physiol., 42, 404-421.

Ingraham, R. C., and Visscher, M. B. (1938). Further studies on intestinal absorption with the performance of osmotic work. Ibid., 121, 771-785.

Kay, A. W. (1953). Effect of large doses of histamine on gastric secretion of $\mathrm{HCl}$ : An augmented histamine test. Brit. med. J., 2, 77-80.

Lieber, C. S., and Lefèvre, A. (1959). Ammonia as a source of gastric hypoacidity in patients with uremia. J. clin. Invest., 38, 12711277.

Milne, M. A., Scribner, B. H., and Crawford, M. A. (1958). Non-ionic diffusion and the excretion of weak acids and bases. Amer. J. Med., 24, 709-729.

Mossberg, S. M., Thayer, W. R., Jr., and Spiro, H. M. (1963). Azotemia and gastric acidity: The effect of intravenous urea on gastric acid and gastric ammonium production in man. J. Lab. clin. Med., 61, 469-475.

Rappoport, W. J., and Kern, F., Jr. (1963). Gastric urease activity in normal subjects and in subjects with cirrhosis. Ibid., 61, 550-559.

Scobie, B. A., and Summerskill, W. H. J. (1964). Reduced gastric acid output in cirrhosis: Quantitation and relationships. Gut, $5,422-428$.

Seligson, D., and Hirahara, K (1957). The measurement of ammonia in whole blood, erythrocytes, and plasma. J. Lab. clin Med., 49, 962-974.

Sherlock, S. (1961). Hepatic coma. Gastroenterology, 41, 1-8.

Turner, M. D., and Arpad, O. A. (1963). Effect of histamine on arterial blood ammonia in man. Nature (Lond.), 198, 590-591. 